\title{
Companies in Indonesia that can get out of the problem of global economic disruption
}

By : Dika Anggara Putra

NRP : 130119046

At present, many companies cannot survive in the face of global economic developments. The level of ease of doing business in Indonesia has also experienced a decline which puts Indonesia currently in 73rd position out of 190 countries, this decline is due to the fact that global economic conditions tend to be sluggish, unbalanced., and is followed by high global financial uncertainty. Economies in other countries such as Europe and China are also experiencing slow growth. In addition, the volume of world trade is also predicted to be low due to the deteriorating trade relations between countries. In an era of economic disruption which is predicted to last a long time, business people in Indonesia are required to continue to reform, innovate and create diversification so that they can survive and compete in the global market. Therefore, many companies are trying the latest management systems to deal with disruptions. global economy with the hope that companies can develop and innovate. From 2016 to 2018 the business developed rapidly and competition was getting tougher. Every company must be able to make adjustments by making changes, experimenting, developing according to the current era, namely the era of the industrial revolution 4.0.

The implementation of good corporate governance quality GCG (Good corporate governance) enables the creation of added value for stakeholders which in time will create sustainable business success. GCG is basically a set of rules that govern, manage, and oversee the relationship between company managers and stakeholders in the company in an effort to increase the value and market of the company. By implementing GCG, the company will get more benefits, such as ensuring the formation of a corporate culture, information disclosure, an effective audit system, and control risks that always refer to GCG standards.

Currently what is happening is an increase in the population of large and medium industries followed by the addition of new workers, especially in industries that are closely related to the use of high technology. The most sought-after workforce are data analytics and business intelligence, digital-based general marketing, and software programmers. The development of the digital economy turns out to make companies look for new workers by prioritizing information technology skills, the quality of manpower development in Indonesia seems to have not been optimal, as reflected in the Labor Development Index which only reached 60.81 in 2018. The Central Government and Regional Governments are trying to realize various project infrastructure , but at the same time, digital technology is growing rapidly which results in the creation of new jobs. job opportunity indicator that rose from 8.56 in 2017 to 11.23 in 2018. Digital trends create 
many job opportunities, but most of them are informal and have no legal status. So, digital technology that moves quickly actually demands a change in skills, considering that these skills are currently owned by workers but are not needed in the future, so new competencies are needed.

Challenges that arise can come from external or internal factors of the company. which means that business transformation and human resource transformation are the most important agendas in many companies. Companies that have succeeded in carrying out business and transforming human resources are PT. BNI, Tbk. and PT. Hartono Indonesia Plantation (HPI-Agro). PT. BNI, Tbk. has carried out a digital banking transformation by launching several digital products, such as mobile banking, digital loans, mobile money transfer, chat banking, and QR Code-based payment applications by preparing millennial talents with different treatment, different learning, and different total prizes. HPI-Agro has carried out 9 transformation businesses in the last 6 years, namely: (1) converting annual crops to seasonal crops; (2) transforming project development into an established organization; (3) change the investment mode to operational mode; (4) transforming administration into strategic manager; (5) converting ad-hoc to planning-based; (6) transforming traditional organizations into modern ones; (7) converting plantations into agricultural industries; (8) converting supply into demand for management; and (9) turning followers into innovators.

Transformation can be done with the aspects of transparency, accountability, responsibility, independence and fairness. Currently, more and more companies in Indonesia are implementing GCG not as a regulatory obligation or something burdensome, but as part of company tools and guidelines to achieve knowledge of the business transformation process. Companies that have implemented GCG are proven to be able to carry out all strategies and management systems properly and correctly and bring the results of stakeholder trust. In general, in terms of output, outcome and impact, companies that have implemented GCG have shown significant progress. Besides being able to encourage aspects of openness, accountability, and trust, GCG also helps empower functions in business units and increases the independence of company organs. It turns out that GCG implementation can be done to encourage companies to continue to create and introduce new values in the aspects of products, operations and services that have an impact on improving company performance, and ultimately benefiting stakeholders. system consistency Sustainable GCG implementation, from the perspective of value creation, is urgently needed in market capitals. Employee involvement is very important in a company that is currently in the vortex of global economic disruption. Employee involvement provides access to management to improve the condition of employees who say, stay, and try through efforts to build high commitment and better accommodate aspects of company employee satisfaction, which in finally can be implemented into daily operational activities. involved employees are expected to foster enthusiasm, motivation and proactive encouragement for employees.

As a conclusion, competitive advantage can be a necessity for every company in Indonesia in the face of global economic disruption when the company wants to survive in the domestic and global markets through transformation at all levels and sustainable business units. Economic disruptions can be overcome by company leaders. Leaders must also strive to be more adaptive in 
facing a future that is full of volatility, uncertainty, complexity, and ambiguity (VUCA), including being able to bring a positive aura to all employees. Furthermore, performance targets need to be lowered from the top level to individuals so that each employee can move in the same direction. In addition, they must be able to cultivate shared values in every employee and be a role model for all employees. The proof is that the implementation of GCG in the company can increase company value, market value, cultural value, information disclosure, the effectiveness of the audit system, and risk control. Maximization benefits can be obtained if governance runs well and is always in line with compliance and conformity to ethics and norms.

\section{References}

Tayibnapis, A. Z., Wuryaningsih, L. E., \& Gora, R. (2019). Advances in Social Science, Education and Humanities Research. Companies in Indonesia in the vortex of global economic disruption,(308). 